\title{
Las enseñanzas de los thrillers epidémicos al estudio de la COVID-19
}

\section{The teachings of the epidemic thrillers to the study of the COVID-19}

\author{
Víctor Grande-Lópeza \\ a Departamento de Marketing y Comunicación, Facultad de Ciencias Sociales y de la Comunicación, Universidad de Cádiz, España
}

\begin{abstract}
Resumen
Introducción: Una excesiva confianza aleja la prevención de lo imprevisible y el cine a través de los thrillers epidémicos ha sido un gran maestro en mantener viva las incertidumbres. Objetivo: Analizar diez películas basadas en enfermedades zoonóticas que a través de sus historias generan ideas para aplicarlas desde una comunicación en salud al estudio de la COVID-19. Metodología: Selección de películas a través de la base de datos IMDb (Internet Movie Date Base), análisis fílmico y valorativo de los textos audiovisuales como obras de comunicación. Resultados: Mostrar epidemias a una cierta distancia desde la pantalla se ven lejanas e improbables pero al final invitan a pensar y dan toques de atención de que algún día esos escenarios pueden convertirse en cercanos y probables. Se destaca de las películas la importancia de mantener distancias entre los animales reservorios y los humanos para lograr evitar futuras zoonosis virales. Conclusiones: Prevenir en salud es cuidar y cuando se afrontan pandemias de rápida propagación e incierta previsión como la COVID-19, la mejor receta para su gestión es aprender de actuaciones pasadas, extraer ideas y encontrar soluciones a nuevas preguntas.
\end{abstract}

Palabras clave: cine; COVID-19; pandemia; educación para la salud; comunicación.

\begin{abstract}
Introduction: Excessive confidence drives prevention away from of the unpredictable, and cinema through epidemic thrillers has been a great master of keeping uncertainties alive. Objective: Analyze ten films based on zoonotic diseases that through their stories generate ideas to apply them from a communication in health to the study of the COVID-19. Methodology: Selection of films through the IMDb (Internet Movie Date Base), filmic analysis and evaluation of audiovisual texts as works of communication. Results: Showing epidemics at a certain distance from the screenseems distant and improbable but in the end they invite thinking and give hints that someday those scenarios may become close and probable. The importance of maintaining distances between reservoir animals and humans to avoid future viral zoonoses is highlighted from the films. Conclusions: Preventing in health is caring and when facing rapidly spreading and uncertain forecast pandemics like COVID-19, the best recipe for its management is to learn from past actions, extract ideas and find solutions to new questions.
\end{abstract}

Keywords: cinema; COVID-19; pandemic; education for the health; communication. 


\section{Introducción}

I al como hace referencia Moratalla (2014, p. 26): "En una sociedad globalizada las fronteras se difuminan y los peligros no se pueden controlar". Y es que a pesar de que uno de los mayores miedos del ser humano a lo largo de la historia ha sido el ser devorado por criaturas extrañas, también existen otros monstruos que vienen en forma de pandemias inesperadas. Enfermedades zoonóticas que ponen a prueba a la medicina y muestran la fragilidad del ser humano (Hormigos, 1998).

Sobre las enfermedades que se transmiten de animales a personas, una de las más devastadoras ha sido La Peste ocasionada por la bacteria zoonótica Yersinia pestis. Ya en el siglo VI, mediante la plaga de Justiniano, perdieron la vida casi 50 millones de personas en todo el mundo. En el siglo XIV La Peste negra provocó la pérdida de 25 millones de personas solo en Europa y casi 60 millones de personas en todo el planeta (Dean et al., 2018). En la pandemia de gripe de 1918, causada por el virus Influenza A subtipo H1N1, perdieron la vida aproximadamente 40 millones de personas (Losada, 2012).Y por el virus de inmunodeficiencia humana (VIH) Deeks, Lewin y Bekker (2017) indican que desde los años 70 ha causado la muerte a 35 millones de personas en todo el mundo (Grande-López, 2019).

La primera pandemia del siglo XXI la provoca el síndrome respiratorio agudo grave (Severe Acute Respiratory Syndrome, SARS-CoV) de 2002-2003 cuya rápida diseminación global se produjo por un desconocimiento inicial del virus y a través del tráfico aéreo internacional. La identificación de las personas contagiadas, el aislamiento como medida de prevención y el seguimiento a las personas que habían tenido contacto previamente con personas contagiadas, lograron frenar la enfermedad no obteniéndose casos desde el año 2004. Posteriormente en 2012 emerge otro coronavirus identificado por primera vez en Arabia Saudita y causante del Síndrome Respiratorio del Medio Este (MERS-CoV). Ambos, tanto el SARS-CoV como el MERS-CoV, son patógenos zoonóticos que se generan en animales infectados y que son transmitidos de animales a humanos (Koury González y Hirschhaut, 2020). La exposición a virus zoonóticos en el mundo cada vez es mayor, por ello los sistemas sanitarios internacionales y los gobiernos deben estar preparados ante la llegada de virus con componente letal, ya que se calcula que existen entre 631.000 y 827.000 virus que podrían ser zoonóticos (Carroll et al., 2018).

Tras expuestos dichos antecedentes, durante el mes de diciembre de 2019 un grupo de científicos chinos alertan sobre un brote de neumonía en la ciudad de Wuhan (China). Siendo el 7 de enero de 2020 cuando lo identifican como un nuevo coronavirus (CoV) y el 20 de enero de 2020 lo denominan nuevo coronavirus 2019 (2019-nCoV) compartiendo el $79.6 \%$ del genoma con el conocido SARSCoV (Wang, Horby, Hayden y Gao, 2020, p. 470). Los primeros datos que se conocen determinan que el síndrome respiratorio agudo grave coronavirus 2 (SARS-CoV-2) es una enfermedad respiratoria por coronavirus causante de la enfermedad COVID-19 que deriva de una infección zoonótica asociada con la venta de animales salvajes en un mercado de Wuhan (China) (Lam et al., 2020).

Sanmartín, Sacedón y Sanjurjo-Sánchez (2020) destacan que en estos últimos años se han publicado estudios sobre la adaptabilidad del cine como recurso educativo, proponiendo actividades didácticas y favoreciendo una visión crítica del alumnado respecto a las películas de catástrofes naturales (Alfaro, Brusi y González, 2008), pandemias o epidemias que se encuentran dentro del tipo de desastres naturales denominados desastres biológicos. Ariza Victoria (2018) indica que el cine sirve de espejo con respecto a los modelos humanos debido a que sus narraciones articulan códigos de comportamiento social. Cuenta con una gran capacidad de influencia por los recursos expresivos (movimientos de cámara, planos, sonido, etc.) que refuerzan su valor comunicativo (Gutiérrez San Miguel, 2006).

Desde esa aportación pedagógica, Casetti (2000) hace referencia a una investigación estético-esencialista ya que las películas son analizadas como reserva de ejemplos, como espacios a interrogar o como estrategias de interpretación (Bordwell, 1995) ya que en todo signo audiovisual, hay un significado referencial y otro implícito. $Y$ desde la ética del filme, se desarrollan preguntas como: ¿qué entiende el espectador cuando ve un filme, cómo y por qué lo entiende, y de qué le sirve? (Vázquez de la Fuente, 2010).

Visionar películas en el aula aumenta en torno a un $50 \%$ la retención de la información con respecto a la lectura del texto solo. Dicha adquisición se produce por la codificación dual (verbal y visual) que al introducir las imágenes en el sistema de procesamiento de información que se almacena junto a la información lingüística, se interconectan propiciando una mejor comprensión y transmisión del contenido (Sanmartín, Sacedón y Sanjurjo-Sánchez, 2020).

El medio cinematográfico ha ido ilustrando enfermedades contagiosas como hilo conductor de sus películas. Comunicando lo insólito e inimaginable y haciendo comprensible lo inesperado. Vizcarra (2003, p. 87) lo subraya como un: "cine de anticipación". 


\section{Objetivo}

El objetivo de este estudio es analizar diez películas basadas en enfermedades zoonóticas que a través de sus historias generan ideas para aplicarlas desde una comunicación en salud al estudio de la COVID-19. "La narración cinematográfica nos puede hacer ver lo improbable como posible, puede ayudar a ponernos en lo peor y ser un buen laboratorio para pensar" (Moratalla, 2014, p. 26).

\section{Metodología}

Se hace referencia al procedimiento metodológico utilizado para un film desde las teorías sobre la narrativa fílmica y la semiótica del relato(Sulbarán Piñeiro, 2016). En primer lugar, se obtienen datos por medio de una revisión bibliográfica de autoras y autores en investigaciones basadas en cine y epidemiología. Seguidamente se establece una búsqueda exhaustiva en la base de datos IMDb (Internet Movie Date Base) de la que se obtienen diez thrillers epidémicos. Se desarrolla un análisis fílmico y valorativo, se lleva la narración fílmica de la imagen al papel por medio de unidades narrativas que contienen una intención comunicativa. Y finalmente, mediante los datos recogidos se realiza su interpretación para obtener los resultados.

Masterman (1993) expone que el análisis de los medios debe ir siempre más allá de la consideración de los significados connotativos y adentrarse en el análisis ideológico. Dicha propuesta se encuentra dirigida al entorno educativo, ya que tal como establecen Astudillo Alarcón y Mendinueta Aguirre (2008) se captan mensajes de los modelos humanos y de la pluralidad de los comportamientos. Y se adquiere una alfabetización audiovisual y sanitaria (Grande-López, 2019). Y es que la evaluación científica que ofrece un filme desde su experiencia estética, lleva a descodificar un texto dándole una significación desde la carga sustantiva, material, narrativa y simbólica (Vázquez de la Fuente, 2010).

\section{Análisis del contenido fílmico a través de los thrillers epidémicos}

Se organiza la información para posteriormente recoger datos más específicos. Se construye en esquemas prototípicos que son identificables en la obra (Bordwell, 1985). Título de la película, país, director, año, enfermedad contagiosa, patógenos, reservorios, síntomas, propagación del virus, personajes de la narración fílmica implicados y comunicación en salud.

Carabias Martín (2006) hace referencia a la película estadounidense Pánico en las calles (Panic in the Streets, Elia Kazan, 1950) basada en un marinero de origen armenio que es asesinado en el puerto de Nueva Orleans (Estados Unidos). Su autopsia confirma que tenía la peste neumónica una infección grave provocada por el patógeno Yersinia pestis y que afecta a los pulmones. Las autoridades sanitarias indican que en menos de 48 horas tienen que aislar a las personas que han tenido contacto con el marinero y poner al barco en cuarentena como medida de prevención. "Los facultativos indican que el problema no son las ratas muertas sino los millones de pulgas que buscan nuevos huéspedes" (Ontoso Picón, 2006 , p. 4). Pulgas que viajan en barcos y provocan la muerte de sus tripulantes incluso antes de llegar a tierra. Marineros que llegan al puerto sin ser conscientes de que llevan pulgas en sus ropas facilitando la propagación de la enfermedad. Tanto el doctor Reed como el capitán de policía inicialmente asumen la decisión de no informar sobre lo ocurrido para evitar el pánico en las calles. Derecho que reclama un periodista amenazando con contar lo ocurrido pero que termina silenciado en la cárcel.

Carabias Martín (2006, p. 92) recuerda que aunque se ve como una enfermedad del pasado: "La peste no es una amenaza de antaño, sino una espada de Damocles que la humanidad tiene sobre su cuello". El doctor Reed advierte en la película del peligro que puede ocasionar que una enfermedad contagiosa se propague, no solo por la ciudad, sino por todo el país o fuera de él convirtiéndose en pandemia. Y es que tal como hace referencia Carabias Martín (2006) en sus estudios, en un mundo que es global es una certeza cada vez mayor que las enfermedades también lo sean.

Las crisis sanitarias donde rápidamente se generan un gran número de fallecimientos despiertan muchas dudas sobre la transparencia de sus gestiones. La película mexicana El año de La Peste (Felipe Cazals,1979) se basa en una enfermedad que inicialmente los sanitarios la vinculan con una bronconeumonía que afecta al aparato respiratorio, pero el incremento rápido de personas fallecidas y los síntomas que presentan comienzan a sospechar que podría ser la peste negra. Los médicos advierten al gobierno sobre la gravedad de la enfermedad para la población, pero éstos optan por la opción de ignorar lo que está ocurriendo para no alarmar. Tras el número de ingresos y el incremento de fallecidos, el gobierno acuerda con las autoridades sanitarias dar instrucciones a la población en la prevención de una infección bronquial aguda y evitan inicialmente inquietar con la gravedad de una enfermedad como la peste. Si advierten, que ante la presencia de ratas lo pongan en 
conocimiento debido a que las pulgas que se hospedan en los roedores son focos de infección.

En la película argentina-francesa y británica La Peste (The Plague, Luis Puenzo, 1993) aparecen ratas muertas en un despacho sanitario en la ciudad de Orán (Argelia). Las autoridades sanitarias no le dan importancia, pero tras el aumento de casos el doctor Rieux decide gestionar la epidemia e informar a los periodistas sobre las formas en las que se puede propagar una enfermedad como la peste bubónica. Siendo una infección bacteriana grave que es transmitida a través de pulgas que se encuentran en ratas. El Doctor Rieux muestra en la película muchas virtudes de un buen médico y además tiene claro lo que implica su profesión: "Soy médico, la enfermedad es mi enemigo natural" (Ontoso Picón, 2006, p. 9). Los ciudadanos acuden a la iglesia desesperados porque no encuentran consuelo a lo que está ocurriendo. El padre Paneloux mediante su sermón predica que la peste es un designio divino, una forma de alcanzar la eternidad. Siendo el doctor Rieux muy crítico con esos comentarios subrayando que: "Si creyera en un Dios todopoderoso, dejaría de practicar la medicina" (Ontoso Picón, 2006, p. 6). Del suero como tratamiento, el Doctor Rieux afirma: "Que el bacilo de la peste no muere ni desaparece sino que permanece acantonado" (Ontoso Picón 2006, p. 7).

Sobre la película estadounidense Estallido (Outbreak, Wolfgang Petersen, 1995) Hormigos Vaquero (1998) establece que se desarrolla en 1967 en el valle del río Motaba (Zaire) donde un virus transmitido de animales a humanos tiene un alto índice de mortalidad en la población. Un virus ficticio denominado Motaba y de características muy parecidas al virus del Ébola (EVE). Tras el ejército estadounidense lanzar una bomba incendiaria en la zona en 1967. 27 años después, en 1994, médicos del ejército norteamericano se dirigen para inspeccionar aquella zona y examinar los motivos por los que el virus todavía sigue siendo letal para la población. Para ello, deciden decretar una alerta sanitaria de la que el general de la brigada se niega, excusando que la enfermedad seguramente desaparezca. Por otra parte, en la misma zona capturan un mono desconociendo que es portador del virus. Lo trasladan en un barco ilegal hasta Estados Unidos y las personas que comienzan a tener contacto con él empiezan a presentar síntomas de la enfermedad. Tras las primeras muertes por contagio, la ciudad de Cedar Creek en California decreta la cuarentena para evitar que el virus se propague.

En la película británica 28 días después (28 days later, Danny Boyle, 2002) un grupo de activistas no son conscientes del riesgo que asumen al entrar en un laboratorio científico con la intención de liberar a unos monos que están siendo utilizados para realizar experimentos no éticos. Tras liberar a uno, un científico advierte que los animales están infectados de una variante del virus de la rabia (RaV) y que pueden enfermar si les muerde. Efectivamente, el mono ataca a una activista infectándola y le provoca un comportamiento violento que hace que se enfrente a sus propios compañeros.

Virus mortal (Fatal Contact: Bird Flu in AmericaTV-, RichardPearce, 2006) esuna películanorteamericana que presenta a un ejecutivo norteamericano que realiza en 6 días, 11 reuniones y en 3 países diferentes. La película se inicia en un mercado de animales vivos en Guangdong (China) donde da origen a un brote del virus llamado H5N1, una enfermedad infecciosa vírica que afecta al ser humano al estar en contacto con aves infectadas. En una de las reuniones que mantiene el ejecutivo en una fábrica de Guangdong, uno de los trabajadores comienza a toser junto a él. De vuelta a Estados Unidos, el ejecutivo ya comienza sin ser consciente a propagar el virus en el aeropuerto y seguidamente dentro del avión. Al llegar a Virginia (Estados Unidos) el ejecutivo tiene el virus de la influenza aviar A (H5N1) y es un riesgo para la población. Al poco tiempo las autoridades sanitarias comienzan a verse desbordadas por síntomas graves en la ciudad y el gobierno declara el estado de alarma a pesar de la diversidad de opiniones.

Sobre otro virus de origen zoonótico contagioso que se produce al tener contacto con aves muertas trata la película estadounidense Pandemia (Pandemic, Armand Mastroianni, 2007) que presenta a dos jóvenes surfistas norteamericanos surfeando en una playa de Sidney (Australia) y alrededor de ellos animales muertos, entre ellos gaviotas marinas. Más tarde, las consecuencias de dicho desastre llevan a que uno de los surfistas aparezca muerto en una cabaña al lado de la playa y el otro dentro de un avión de vuelta a Los Ángeles (California). Los síntomas que mostraron fueron leve tos, fiebres altas y síndrome de distrés respiratorio agudo que derivó en fallecimiento. Al aterrizar el avión donde se encontraba viajando el surfista como medida de prevención se pone en cuarentena a todos los pasajeros. El gobierno tiene discrepancias en el aeropuerto sobre las medidas sanitarias y también les incomoda que se encuentren presentes los medios de comunicación. Uno de los pasajeros escapa de la cuarentena y pone en riesgo a los habitantes de la ciudad propagándose rápidamente el virus.

Otra película estadounidense sobre un virus ficticio denominado MEV-1 pero que tiene similitud con el 
virus Nipah (VNi) es Contagio (Contagion, Steven Soderbergh, 2011). La infección por zoonosis viral se produce en Hong Kong (China) donde una ejecutiva norteamericana se contagia, a su vuelta a Minneapolis (Estados Unidos) comienza a propagar el virus y la población comienza a tener síntomas de los que creen que es debido a una simple gripe. Las autoridades militares advierten a uno de los responsables sanitarios que no deben de dar información sobre lo que está ocurriendo para que no se propague el miedo, pero el gobierno comienza a sospechar sobre la información que circula por internet y periodistas y autoridades sanitarias también tienen pulsos y desacuerdos en la televisión con respecto a cómo se está gestionando todo.

Sobre el virus de la influenza aviar A (H5N1), altamente contagioso que siembra el pánico en Bundang-gu (Corea del Sur), la película surcoreana Virus (Gamgi, The Flu, Kim Sung-su, 2013) se desarrolla a través de unos inmigrantes ilegales de Hong-Kong que llegan a Bundanggu en un contendedor de transporte lleno de roedores. Las personas que tienen contacto con el contenedor empiezan a presentar tos y síntomas graves. Tras recomendar las autoridades sanitarias aislar la ciudad de Bundang-gu, existe disconformidad por parte del gobierno que no cree la necesidad de aislar la ciudad. El ministro indica que el miedo puede ser peor que el virus, debate sobre la propagación de rumores en las redes sociales e insinúa incluso en restringir la red de internet. Los ciudadanos salen a la calle generando disturbios como medidas de reivindicación ante la situación en la que se encuentran.

Finalmente, se destaca en el estudio 93 días (93 days, Steve Gukas, 2016) una película nigeriana basada en hechos reales donde se refleja el lado más humano de los profesionales de la sanidad. Trata sobre la llegada a un hospital de Lagos (Nigeria) de un paciente directamente del aeropuerto y que tras los resultados de unas pruebas que le realizan da positivo en el virus del Ébola. Los sanitarios del hospital estuvieron días previos al resultado de las pruebas en contacto con el paciente y no se protegieron. Eso lleva a que les surjan incertidumbres si están contagiados 0 si han podido contagiar a sus propios familiares. Muchas dudas y poca ayuda, ya que una de las responsables del hospital informó a la Oficina del Gobernador sobre un posible caso del virus y le recomendaron que no hiciera nada público.

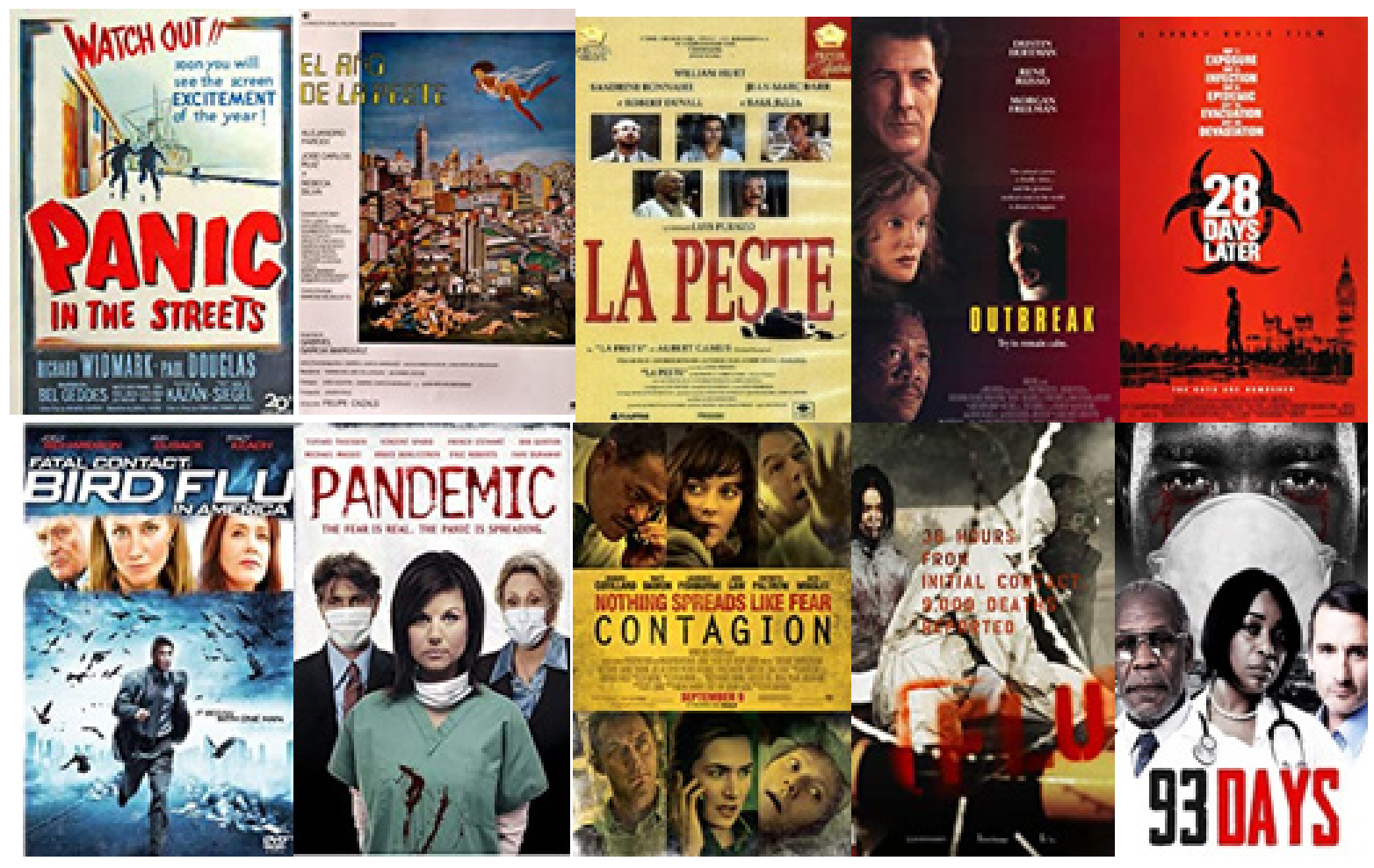

Figura 1. Mosaico de la cartelera cinematográfica de las películas del estudio.Fuente: elaboración propia e imágenes IMDb (Internet Movie Date Base). 
Tabla 1.Datos extraídos del análisis de los thrillers epidémicos.

\begin{tabular}{|c|c|c|}
\hline Título de la película & Enfermedad & Comunicación en salud \\
\hline $\begin{array}{l}\text { Pánico en las calles (Panic in } \\
\text { the Streets, Elia Kazan, 1950) }\end{array}$ & Peste neumónica & $\begin{array}{l}\text {-Bacteria Yersinia pestis. } \\
\text {-Contagios provocados por pulgas de } \\
\text { roedores a humanos. } \\
\text {-El gobierno inicialmente no ve peligro para } \\
\text { la salud pública. } \\
\text {-Silencian a los medios de comunicación } \\
\text { para que no informen sobre la enfermedad. } \\
\text {-Cuarentena. } \\
\text {-Búsqueda de personas que han tenido } \\
\text { contacto con el enfermo. }\end{array}$ \\
\hline $\begin{array}{l}\text { El año de La Peste (Felipe } \\
\text { Cazals,1979) }\end{array}$ & $\begin{array}{l}\text { Peste bubónica (peste negra } 0 \\
\text { muerte negra) }\end{array}$ & $\begin{array}{l}\text {-Bacteria Yersinia pestis. } \\
\text {-Contagios provocados por pulgas de } \\
\text { roedores a humanos. } \\
\text {-El gobierno trata de ocultar la enfermedad } \\
\text { y la relaciona con una infección bronquial } \\
\text { aguda. } \\
\text {-El sistema sanitario es cómplice. } \\
\text {-Existen presiones a los medios. } \\
\text {-Vacaciones en las escuelas como medida } \\
\text { de prevención. } \\
\text {-Búsqueda de personas que han tenido } \\
\text { contacto con el enfermo. } \\
\text {-Edificios evacuados y sellados con cintas } \\
\text { amarillas en forma de equis. } \\
\text {-Muchos de los fallecidos no son pasados } \\
\text { por el registro de defunción. }\end{array}$ \\
\hline $\begin{array}{l}\text { La Peste (The Plague, Luis } \\
\text { Puenzo, 1993) }\end{array}$ & Peste bubónica & $\begin{array}{l}\text {-Bacteria Yersinia pestis. } \\
\text {-Contagios provocados por pulgas de } \\
\text { roedores a humanos. } \\
\text {-Se anuncia previamente un diagnóstico } \\
\text { falso para tranquilizar a los ciudadanos } \\
\text { diciendo que es fiebre tifoidea, con } \\
\text { adenopatías y vómitos. } \\
\text {-Se aísla a las personas como medidas de } \\
\text { prevención. } \\
\text {-Se amplían camas para pacientes en un } \\
\text { recinto cubierto. } \\
\text {-Mascarillas quirúrgicas. } \\
\text {-Fosas comunes a fallecidos. } \\
\text {-Suero antipestoso. }\end{array}$ \\
\hline
\end{tabular}


Tabla 1. Continuación.

\begin{tabular}{|c|c|c|}
\hline Título de la película & Enfermedad & Comunicación en salud \\
\hline $\begin{array}{l}\text { Estallido (Outbreak, Wolfgang } \\
\text { Petersen, 1995) }\end{array}$ & $\begin{array}{l}\text { Virus Motaba (ficticio pero pare- } \\
\text { cido al virus del Ébola) }\end{array}$ & $\begin{array}{l}\text {-Lanzamiento de una bomba para eliminar } \\
\text { el virus en la zona. } \\
\text { - Recomiendan mantener el virus en } \\
\text { secreto. } \\
\text {-Difíciles relaciones entre los medios } \\
\text { de comunicación, los médicos, los } \\
\text { investigadores, el poder político y militar. } \\
\text { - Suero ficticio llamado E-1101 como } \\
\text { tratamiento al virus. }\end{array}$ \\
\hline $\begin{array}{l}28 \text { días después (28 days } \\
\text { later, Danny Boyle, 2002) }\end{array}$ & $\begin{array}{l}\text { Enfermedad zoonótica viral } \\
\text { infecciosa (parecida al virus de } \\
\text { la rabia) }\end{array}$ & $\begin{array}{l}\text {-El virus ataca al sistema nervioso. } \\
\text {-Investigadores utilizan monos para } \\
\text { experimentos científicos. } \\
\text {-El virus se propaga muy rápido. } \\
\text { convirtiendo a toda la población en } \\
\text { personas agresivas. }\end{array}$ \\
\hline $\begin{array}{l}\text { Virus mortal (Fatal Contact: } \\
\text { Bird Flu in America (TV), } \\
\text { Richard Pearce, 2006) }\end{array}$ & Virus influenza A subtipo H5N1 & $\begin{array}{l}\text {-En un mercado de China se produce un } \\
\text { brote del virus H5N1. } \\
\text {-El gobierno no quiere alarmar a los } \\
\text { ciudadanos. } \\
\text {-Aislamiento de las personas siendo } \\
\text { controladas por la policía. } \\
\text {-Lavado de manos y mascarillas. } \\
\text {-Los ciudadanos arrasan con los productos } \\
\text { en los supermercados. } \\
\text {-Suben los precios. } \\
\text { - Las autoridades sanitarias necesitan } \\
\text { ayuda. } \\
\text {-Irresponsabilidad ciudadana. }\end{array}$ \\
\hline $\begin{array}{l}\text { Pandemia (Pandemic, Armand } \\
\text { Mastroianni, 2007) }\end{array}$ & Virus de origen zoonótico H3N7 & $\begin{array}{l}\text {-Aislamiento de pasajeros. } \\
\text {-Fases del virus: leve tos, fiebres altas y } \\
\text { síndrome de distrés respiratorio agudo. } \\
\text {-Mascarillas en las calles. } \\
\text {-Ciudadanos arrasan con productos en los } \\
\text { supermercados. } \\
\text {-Difíciles relaciones entre los medios de co- } \\
\text { municación, los médicos y el poder político. } \\
\text {-Control militar en la entrada/salida de la } \\
\text { ciudad. } \\
\text {-Irresponsabilidad ciudadana. }\end{array}$ \\
\hline
\end{tabular}


Tabla 1. Continuación.

\begin{tabular}{|c|c|c|}
\hline Título de la película & Enfermedad & Comunicación en salud \\
\hline $\begin{array}{l}\text { Contagio (Contagion, Steven } \\
\text { Soderbergh, 2011) }\end{array}$ & $\begin{array}{l}\text { Virus ficticio denominado MEV-1 } \\
\text { (Parecido al virus H1N1/09 } \\
\text { pandémico) }\end{array}$ & $\begin{array}{l}\text {-Huésped el murciélago e intermediario el } \\
\text { cerdo. } \\
\text {-Se cree inicialmente que es una simple } \\
\text { gripe. } \\
\text {-Las autoridades militares advierten a } \\
\text { sanitarios que no deben informar sobre } \\
\text { lo que está ocurriendo para que no se } \\
\text { propague el miedo en la población. } \\
\text {-El orden de la vacuna lo deciden por fecha } \\
\text { de nacimiento. } \\
\text {-A las personas vacunadas se les pone una } \\
\text { pulsera azul. }\end{array}$ \\
\hline $\begin{array}{l}\text { Virus (Gamgi, The Flu, Kim } \\
\text { Sung-su, 2013) }\end{array}$ & Virus influenza A subtipo H5N1 & $\begin{array}{l}\text {-El virus es importado por inmigrantes } \\
\text { ilegales. } \\
\text {-Las personas que han tenido contactos } \\
\text { con personas enfermas empiezan a tener } \\
\text { tos y síntomas graves. } \\
\text {-Los teléfonos de emergencia se colapsan. } \\
\text {-Existe disconformidad por parte del } \\
\text { gobierno. } \\
\text {-El ministro indica que el miedo puede ser } \\
\text { peor que el virus. } \\
\text {-El médico alerta que se debe informar } \\
\text { dando prioridad al contagio. } \\
\text {-Supermercados colapsados. } \\
\text {-El gobierno debate para que no se } \\
\text { promuevan rumores en las redes sociales. } \\
\text {-El gobierno se plantea restringir la red de } \\
\text { internet. } \\
\text {-Los ciudadanos generan disturbios en las } \\
\text { calles. }\end{array}$ \\
\hline $\begin{array}{l}93 \text { días (93 days, Steve Gukas, } \\
2016 \text { ) }\end{array}$ & Virus del Ébola & $\begin{array}{l}\text {-Falta de protección en sanitarios. } \\
\text {-La Oficina del Gobernador ante posibles } \\
\text { casos recomienda a los sanitarios que no } \\
\text { se haga público. } \\
\text {-Difícil controlar un virus en una ciudad de } \\
\text { más de } 21 \text { millones de habitantes. } \\
\text {-El tráfico aéreo global facilita la } \\
\text { propagación. }\end{array}$ \\
\hline
\end{tabular}

Fuente: elaboración propia. 


\section{Resultados}

A continuación, se indican los resultados que se han obtenido del análisis de los thrillers epidémicos al estudio del coronavirus SARS-CoV-2.

Las películas, presentadas desde una mirada pedagógica-visual, sirven para aprender a valorar la diversidad de las imágenes que circulan en la cotidianidad y saber ver mejor el mundo que nos rodea (Dussel y Gutiérrez, 2006). Todas las películas, al igual que la COVID-19, tienen en común que el virus surge de un brote epidémico que se transmite de los animales a los seres humanos. Sitúan el foco en mercados asiáticos donde determinadas prácticas con animales salvajes vivos derivan a infecciones contagiosas en seres humanos. Siendo importante establecer la lejanía, entre los animales reservorios y los humanos y así evitar futuras zoonosis virales.

Con respecto al patógeno de la enfermedad COVID-19, es el coronavirus SARS-CoV-2, pero el reservorio está aún en periodo de investigación. En la enfermedad de la peste causada por la bacteria Yersinia pestis, actúa como reservorio los roedores y como vector las pulgas. Dean et al., (2018) indican que durante el siglo XIV la peste negra causó una alta mortalidad y se vinculó inicialmente con las pulgas de los roedores comensales. Pero dichos autores obtienen como resultados en sus estudios que los vectores de ectoparásitos humanos como las pulgas humanas (Pulex irritans) o los piojos del cuerpo (Pediculus humanus humanus) fueron los causantes de la rápida propagación en ese periodo concreto. En la película Virus mortal (Fatal Contact: Bird Flu in America -TV-, Richard Pearce, 2006) el patógeno que se indica es el virus de Influenza A subtipo H5N1, que es una cepa de gripe aviar cuyo reservorio son las aves. Y que al igual que con la COVID-19, el brote epidémico lo localizan en un mercado de China.

La forma de propagación de las enfermedades contagiosas que aparecen en las películas del estudio coincide mayoritariamente con la enfermedad de la COVID-19, se propagan a través de micro gotas que contienen virus o bacterias, se expulsan por la nariz y la boca, y debido al respirar, toser, estornudar o hablar a una distancia cerca. También al estar en exposición con animales muertos 0 infectados. $Y$ al estar en contacto con superficies u objetos que estén contaminados. Con respecto a la falta de protección que los sanitarios han tenido en los inicios de la imprevisible pandemia, la película 93 días (93 days, Steve Gukas, 2016) hace referencia al riesgo que tienen los profesionales de la salud cuando no están correctamente equipados con los
Equipos de Protección Individual (EPI). Berry y Seltman (2008) destacan en sus estudios la labor visionaria de los profesionales de la salud, los califican como ingenieros y artistas. Ingenieros porque ven el problema y lo resuelven. $Y$ artistas porque conocen cuando el paciente necesita una sonrisa, una palabra reconfortante o un gentil abrazo.

El avión ha sido el medio de transporte que ha favorecido la rápida expansión del virus en las películas, al igual que en la COVID-19, convirtiendo una epidemia en una pandemia en cuestión de horas y propagándose con mucha facilidad entre diferentes continentes. Viene debido a las distancias cortas de los asientos y a las distancias largas en los trayectos. $Y$ un ejemplo sobre la dificultad de gestionar una infección contagiosa con el espacio aéreo abierto, se destaca en la película 93 días (93 days, Steve Gukas, 2016) donde en una ciudad como Lagos (Nigeria) que es el centro del tráfico aéreo en África Occidental, salen docenas de vuelos diariamente que conectan con las principales ciudades del mundo.

Ontoso Picón (2006) expone resultados interesantes de la película El año de La Peste (Felipe Cazals, 1979) que se pueden aplicar al inicio del brote de la enfermedad COVID-19. Y es el miedo e inquietud que le provoca a la población el enfrentarse a una enfermedad que desconocen. No tienen suficiente información y lo único que les llega son números de fallecidos que van incrementándose diariamente. En la película se suma al desconocimiento real de la situación, la actitud que muestra el responsable sanitario al falsear la situación que está ocurriendo trasladando el mensaje de que los casos que se están presentando no son más que una fiebre tifoidea, con adenopatías y vómitos.

Sobre comunicación en salud en las películas del estudio, al igual que en la COVID-19, la expansión del virus se vio favorecida debido a que las autoridades sanitarias e investigadores, inicialmente no le prestaron la suficiente atención ya que no lo veían como un riesgo tan grave debido a la experiencia que tenían con coronavirus previos. Al no existir un diagnóstico claro desde el principio, los protocolos no estuvieron acertados en los inicios del brote en China. El cómo informar sin generar alarma social, el papel de la prensa al empezar a informar sobre una noticia que no se sabe cómo reaccionarán los ciudadanos o hasta qué punto se debe mantener en reserva la información por parte de los agentes implicados. Son algunos de los resultados que se obtienen de las películas y que conjugan también con lo sucedido en el transcurso de la crisis sanitaria de la COVID-19.

La experiencia previa, es un gran paso para actuar con rapidez y efectividad. $Y$ eso se ha demostrado en 
países asiáticos que a priori tenían más experiencia en brotes epidemiológicos, con respecto a los países europeos o americanos. En El año de La Peste (Felipe Cazals, 1979) también se dibuja un escenario de desconocimiento y de medidas de prevención muy necesarias pero aplicadas tarde, entre ellas: decretar el estado de emergencia, adelantar las vacaciones en las escuelas para cerrarlas, ventilar las casas, mantener una buena higiene personal, no comer frutas y verduras crudas, hervir el agua o la leche. Ante síntomas que encuentren extraños les indican como instrucciones que rápidamente pongan en conocimiento a las personas que se han tenido contactos previos. $Y$ una de las cosas que llama la atención con respecto al personal sanitario, es que en películas, incluso del año 1979, contaban con buenos equipos de protección individual (EPI) y las mascarillas que utilizaban no eran las quirúrgicas, sino mascarillas filtrantes de alta eficacia para hacer frente a aerosoles de alta toxicidad.

Otras medidas de prevención que se destacan en las películas La Peste (The Plague, Luis Puenzo, 1993), Virus mortal (Fatal Contact: Bird Flu in AmericaTV-, Richard Pearce, 2006), Pandemia (Pandemic, Armand Mastroianni, 2007), Contagio (Contagion, Steven Soderbergh, 2011) o Virus (Gamgi, The Flu, Kim Sung-su, 2013) y que coinciden con las utilizadas en la COVID-19. Son el aislamiento de personas en sus domicilios, el lavado de manos, usar mascarillas en la calle, distancias de seguridad de 3 metros entre personas, accesos de entradas y salidas de las ciudades cerrados, la cuarentena como medida preventiva, la habilitación de estadios para poder acoger a los pacientes y el colapso de los teléfonos en urgencias.

Se obtiene también como resultados lo importante que es que las personas se encuentren bien informadas a través de fuentes oficiales y no por cualquier medio no oficial, debido a que pueden existir errores, desinformación, noticias falsas, que puedan confundir a la población y actuar de una manera incorrecta.

Los supermercados en las películas se ven desbordados, al igual que en los inicios de la crisis sanitaria de la COVID-19. Compras compulsivas llevadas a cabo por el pánico del virus, que se suman a las restricciones impuestas por el confinamiento que obligaron a que determinadas empresas dejaran de exportar sus productos y cuyo efecto lleva a una subida de precios. En películas como Virus mortal (Fatal Contact: Bird Flu in America-TV-, Richard Pearce, 2006), Pandemia (Pandemic, Armand Mastroianni, 2007) o Virus (Gamgi, The Flu, Kim Sung-su, 2013) muestran como multitud de ciudadanos hacen cola y arrasan con los productos dejando las estanterías vacías, actitud que provoca que unas semanas después subieran los precios en los productos de primera necesidad.

Una crisis sanitaria que deriva a una económica, obteniéndose datos interesantes en la película El año de La Peste (Felipe Cazals, 1979) con respecto a lo sucedido también en la gestión del COVID-19, y es que el gobierno en la película indica que si se declara el estado de emergencia se dejaría de ser económicamente efectivo en menos de dos semanas, tendrían graves problemas de orden público, conflictos con los sindicatos y las consecuencias en el turismo serían catastróficas.

Con respecto a la irresponsabilidad ciudadana, la película Estallido (Outbreak, Wolfgang Petersen, 1995) deja una expresión coloquial denominada Outbreak monkey para referirse a las personas que sabiendo que tienen una enfermedad contagiosa no rehúye del contacto con los demás y voluntariamente acude a su puesto de trabajo 0 a clases en la escuela pudiendo contagiar a las personas que les rodean.

Para finalizar este apartado, se indican algunos resultados extraídos de los tratamientos que aportan las películas para conseguir frenar las enfermedades contagiosas. En La Peste (The Plague, Luis Puenzo, 1992), como tratamiento emplean un suero antipestoso que logra que la epidemia pierda intensidad. En Virus mortal (Fatal Contact: Bird Flu in America-TV-, Richard Pearce, 2006), los epidemiólogos buscan desesperadamente una vacuna, aunque en realidad el virus $\mathrm{H} 5 \mathrm{~N} 1$ actualmente no cuenta con ninguna vacuna comercial. En Pandemia (Pandemic, Armand Mastroianni, 2007) descubren que a través de anticuerpos de personas enfermas de tuberculosis pueden curar a los infectados dándoles inmunidad, siendo la producción de anticuerpos una de las estrategias que desarrolla el sistema inmunitario para erradicar los virus. Contagio (Contagion, Steven Soderbergh, 2011) detectan, en el Centro para el Control y Prevención de Enfermedades en Atlanta (Estados Unidos), que el virus ficticio denominado MEV-1 es muy parecido al virus Nipah (VNi), cuyo huésped es el murciélago y el intermediario el cerdo. Indican en la película que el virus penetra en células pulmonares y cerebrales, y que contiene secuencias de murciélago y cerdo. El equipo de investigación reflexiona sobre si algún día se consiguiera una vacuna como se gestionaría al estar tantas personas infectadas: ¿Quiénes serían los primeros en vacunarse? Se finaliza el apartado de resultados con el virus de la influenza aviar A (H5N1) que aparece en la película Virus (Gamgi, The Flu, Kim 
Sung-su, 2013) y en el que muestran como tratamiento anticuerpos de una superviviente de la gripe.

\section{Conclusiones}

Las películas interpretan mundos que se visualizan como improbables y a una gran distancia. Pero tal como se ha mostrado en el estudio, dichos espacios son más probables de lo que se pueda pensar. Cuando se visionan situaciones de riesgos las personas que se encuentran visionando el contenido rompen los horizontes de expectativas y activan un pensamiento divergente desde el cerebro emocional, anticipándose a través de ideas para poder solucionar los problemas a los que se enfrentan los protagonistas. La imaginación, desde un enfoque educativo, genera una reacción, ya que lleva a pensar en cómo se actuaría mejor ante dichas amenazas o cómo deberían de actuar los protagonistas de las historias ante los imprevistos que van sucediendo durante el metraje. Al ir las líneas argumentales centradas en la presentación de problemas sirven para enseñar a pensar, por ello no deben ser vistas las películas solo como vehículos lúdicos sino también como recursos pedagógicos.

La narración fílmica sobre desastres biológicos, de una manera visual y verbal, aporta a través de la alfabetización audiovisual y sanitaria un gran valor cognitivo y emocional, debido a los logros, incertidumbres, injusticias o pérdidas que se producen durante el metraje, todo un aprendizaje que lleva a una reflexión y sentido crítico.

Una vez ocurrida una pandemia global como la COVID-19 es necesario en vez de preguntarse: ¿Por qué ha tenido que pasar todo esto?, cambiar la pregunta por: ¿Qué hemos aprendido de todo esto? Ya que el pasado no se ha podido evitar es necesario construir un mejor presente, aprendido del pasado para tener un buen futuro. Los thrillers epidémicos han mostrado en el estudio muchas de las medidas que se han aplicado durante la gestión de la COVID-19 y es que además de una crisis sanitaria y económica, no se debe olvidar que engloba una crisis de incertidumbres.

Se tienen que cambiar hábitos con respecto a la interacción entre los seres humanos, los animales y el medio ambiente. La intromisión del ser humano en el entorno natural y sus prácticas no éticas, se ha visto claramente reflejada en las enfermedades infectocontagiosas que han aparecido en las películas del estudio. Animales vivos sacrificados, capturados estando en peligro de extinción, mezclados entre salvajes y domésticos. Son prácticas que además de incumplir las medidas de higiene, alteran el equilibrio natural y terminan ocasionando una amenaza global para la salud pública. Eliminar el tratamiento que reciben es el primer paso para evitar futuras enfermedades contagiosas. Para ello, es importante revisar la sobre explotación que se está realizando de las especies, los animales salvajes están perdiendo sus territorios y se ha visto claramente que cuando el ser humano se ha escondido, los animales han aparecido y la atmosfera se ha limpiado.

Por otro lado, reaccionar rápido ante enfermedades contagiosas es vital independientemente de su grado de letalidad, ya solo saber que el virus se propaga es más que evidente la necesidad de frenar su propagación. Un virus puede que no tenga consecuencias graves letales a priori, pero si a posterior. Por eso al inicio de toda enfermedad contagiosa antes de evaluar es necesario actuar, ya que de lo contrario puede ser tarde, como se ha demostrado en la COVID-19 que mientras se estaba gestionando los posibles escenarios para su prevención el virus ya había viajado en avión por todo el mundo.

Otro aprendizaje de esta crisis es la importancia de dotar a los sistemas sanitarios de material e infraestructuras necesarias para enfrentarse a desastres biológicos. En un momento donde el ser humano estaba con toda su energía focalizada en el desarrollo de la inteligencia artificial en la medicina, la robótica para intervenciones quirúrgicas, todo con el objetivo de mejorar la calidad de vida de las personas y obtener una mayor longevidad, llega de repente un virus de una dimensión de entre 10 y 100 nanómetros y logra parar a todo el planeta.

Con respecto a la comunicación en salud, una vez que se registran los primeros casos de una enfermedad como la COVID-19 es importante una buena comunicación a la población sobre las correctas medidas en prevención. Si el mensaje que se transmite al igual que en las películas, genera dudas, tiene cambios constantes, ocultan diagnósticos, se basan en contradicciones y se acumulan errores, finalmente genera una gran inseguridad, falta de confianza que puede derivar a no creer fielmente en el mensaje correcto, pudiéndose actuar finalmente de una manera incorrecta.

Como futuras líneas de investigación se pueden desarrollar estudios referentes a películas que traten desastres naturales desde la comunicación en salud pero desde otras perspectivas, como tsunamis o terremotos, que no solamente dejan daños físicos sino psicológicos. También son necesarios estudios sobre la alteración que está produciendo el ser humano al medio ambiente, las mascarillas y los guantes utilizados como prevención para la COVID-19 se están encontrando en el mar, siendo peligroso para el planeta.

El cine, como medio de educación no formal, ha enseñado en este estudio que el virus cuanto antes se 
actúe antes se controla, que no quiere decir que se frene, al igual que los pacientes que se recuperan no significa que estén completamente curados. Que el virus antes viajaba en barcos comerciales y ahora viaja en avión paseándose por los distintos continentes en cuestión de horas. Que al no contar con un tratamiento eficaz para erradicarlo la mejor vacuna para frenarlo es el aislamiento. $Y$ para concluir, las películas como recurso didáctico generan un aprendizaje observacional que activa la empatía cognitiva y visual y desde un lenguaje multisensorial se origina una estética atrayente promoviendo una mayor conciencia y aprendizaje en educación sanitaria.

\section{Referencias bibliográficas}

Alfaro, P., Brusi, D., González, M. (2008). El cine de catástrofes, iqué catástrofe de cine!. En: A. Calonge, L. Rebollo, M.D. López-Carrillo, A. Rodrigo e I. Rábano (eds.), Actas del XV Simposio sobre Enseñanza de la Geología. Cuadernos del Museo Geominero, 11. Instituto Geológico y Minero de España, 1-12.

Ariza Victoria, L. M. (2018). Cine y catástrofe: un escenario decolapso social ante una crisis global. (Tesis doctoral) Universidad Complutense de Madrid, España.

Astudillo Alarcón, W., y Mendinueta Aguirre, C. (2008). El cine como instrumento para una mejor comprensión humana. Revista de Medicina y Cine, 4, 131-136.

Berry, L.,y Seltman, K. (2008). Management lessons from Mayo Clinic: inside one of the world's most admired service organizations. New York: McGraw-Hil.

Bordwell, D. (1985). Narration in the Fiction Film. Wisconsin, EUA: The University of Wisconsin Press.

Carabias Martín, F. (2006). La amenaza de las plagas: Pánico en las calles (1950). Revista Medicina Cine, 2, 89-95.

Carroll, D.,Daszak, P., Wolfe, N., Gao, G., Morel, C., Morzaria, S., ...Mazet, J. (2018). The Global Virome Project, Science, 23, 872-874.

Casetti, F. (2000). Teorías del cine. Madrid, España: Cátedra.

Dean, K., Krauer, F.,Walløe, L.,Lingjærde, O. C.,Bramanti,
B.,Stenseth, N., y Schmid, B. (2018). Human ectoparasites and the spread of plague in Europe during the Second Pandemic. PNAS, 6, 1304-1309.

Deeks, S. G., Lewin, S. R., y Bekker, L. G. (2017). The end of HIV: still a very long way to go, but progess continues. PLoSMed, 14, 1-4.

Dussel, I., y Gutiérrez, D. (2006). Educar la mirada. Políticas y pedagogías de la imagen. Buenos Aires, Argentina: Editorial Manantial /Fundación OSDE.

Grande-López, V. (2019). Una mayor empatía al VIH/sida a través de la educomunicación. Revista Española de Comunicación en Salud, (10)1, 102-108.

Gutiérrez San Miguel, B. (2006). Teoría de la narración audiovisual. Madrid, España: Cátedra.

Hormigos, M. (1998). El cine a las puertas del siglo XXI: las imágenes apocalípticas del fin del mundo. Revista Latina de Comunicación Social, 8.

Koury González, J. M. y Hirschhaut, M. (2020). Reseña histórica del COVID-19 ¿Cómo y por qué llegamos a esta pandemia? Acta Odontológica Venezolana, 58(extra 1), 3-4.

Lam, T.T., Shum, M.H.,Zhu, H.,Tong Y., Ni, X., Liao, Y.,...Guan, Y.(2020). Identifying SARS-CoV-2 relatedcoronaviruses in Malayanpangolins. Nature, https://doi.org/10.1038/s41586-020-2169-0

Losada, J. C. (2012). La gripe española. La aventura de la Historia. Madrid, España: Arlanza Ediciones.

Masterman, L. (1993). La enseñanza de los medios de comunicación. Madrid, España: De la Torre.

Moratalla, T. (2014). Ponernos en situación. Estallido. Bioètica \& debat, 20, 26-27.

Ontoso Picón, D. (2006). La Peste (1992). De Albert Camus a Luis Puenzo. Revista Medicina Cine, 2, 3-9.

Sanmartín, P., Sacedón, M., y Sanjurjo-Sánchez, J. (2020). Rigor científico en películas recientes de catástrofes. Revista Electrónica Interuniversitaria de Formación del Profesorado, 23(2). 
Sulbarán Piñeiro, E. (2016). El análisis del film: entre la semiótica del relato y la narrativa fílmica. Opción, 31, 44-71

Vázquez de la Fuente, M. (2010). Análisis fílmico e interpretación: Epistemología de los modos de significación. Cuaderno de documentación multimedia, 21, 249-277.

Vizcarra, F. (2003). El cine futurista y la memoria del porvenir, Estudios sobre las Culturas Contemporáneas, 18, 87-101

Wang, C.,Horby, W. P.,Hayden, F. y Gao, G. (2020). A novel coronavirus Outbreak of global healthconcern. The Lancet. doi:10.1016/s0140-6736(20)30185-9 